\title{
LEGADOS DAS MEMÓRIAS DA GUERRA COLONIAL: ALGUMAS REFLEXÕES CONCEITUAIS SOBRE A TRANS- MISSÃO INTERGERACIONAL DO TRAUMA
}

\author{
Roberto Vecchi \\ (Università di Bologna)
}

\section{RESUMO}

$\mathrm{O}$ artigo analisa algumas das teorias dominantes em torno do conceito, controverso, de pós-memória. A pós-memória, de fato, como possibilidade de transmissão intergeracional da memória, em particular traumática, sobretudo para pessoas da esfera familiar que não viveram a experiência em causa mas mantêm um laço afetivo com quem a vivenciou, proporciona a possibilidade de rever criticamente alguns processos de fixação da memória tout-court, na sua relação tensa com a possibilidade de uma contratualização histórica. O caso associado a esta conceitualização é aquele da Guerra Colonial que Portugal combateu em África por mais de uma década (1961-1974) e que incidiu profundamente tanto na ontologia do País pós Revolução dos Cravos, como na consciência dos ex combatentes que vivenciaram as experiências traumáticas projetando a impossibilidade de simbolização dos traumas nas relações familiares. Também, pelo mito de Filomela, é analisada uma parte da produção cultural portuguesa das segundas gerações que procura vocalizar estes silêncios doloridos dos pais.

PALAVRAS-CHAVE: Pós-memória, Memória traumática, Segunda geração, Guerra Colonial, Cultura portuguesa contemporânea

\section{ABSTRACT}

The article takes into account some dominant theories about the controversial concept of post- memory. Post- memory, in fact, as the possibility of an intergenerational transmission of memory, particularly traumatic, especially for people belonging to the familiar sphere that didn't live the experience in question but maintain an emotional tie with the direct witnesses, provides the ability to critically review the fixation of memory processes in their tense relationship with the possibility of a contractualization of history. The case associated with such a conceptualization is the Colonial War that Portugal fought in Africa for over a decade (1961-1974) and heavily 
conditioned both the ontology of the country after the Carnation Revolution and the consciousness of the former combatants who lived traumatic experiences projecting the impossibility of their symbolization on family relationships. Besides, through the myth of Philomel, the article approaches part of the contemporary Portuguese cultural production of the second generation, trying to vocalize the painful silences of their parents.

KEYWORDS: Post- memory, Traumatic memory, Second generation, Colonial War, Contemporary Portuguese Culture

O projeto "Os Filhos da Guerra Colonial”, realizado pelo Centro de Estudos Sociais da Universidade de Coimbra entre 2007 e-2011 e coordenado por Margarida Calafate Ribeiro, ${ }^{1}$ articulou uma constelação conceptual criticamente densa e não menos problemática: memória e pós-memória, testemunho, transferência de memória, reconhecimento, só para ficarmos naqueles conceitos que melhor nos situam no campo de uma reflexão teórica relacionada com a projeção do trauma no horizonte cultural, que é um dos eixos do projeto de investigação. Poderíamos dizer que tal perspectiva está relacionada integralmente com a preocupação profunda que, tendo atravessado os estudos de cultura sobre o século $\mathrm{XX}$, suscita multíplices interrogações: a aporia da representação, referindo-se, em particular, à experiência traumática, na sequência do repertório de horrores que estruturou o séculs dos extremosa Neste quadro, no entanto, há um conceito - provavelmente o mais problemático e o menos configurado, ainda que inserido num quadro geral altamente instável do ponto de vista crítico - que, na nossa discussão, não só incorpora de modo emblemático e não redutor muitos dos problemas conceptuais em que se debate o projets dos filhos da guerra colonial, como tambée pode desvendar, se oportunamente colocado, o duplo gume, teórico e político, nele implicado. Trata-se dm conceito, de algum modo em voga nestes anos, de pós-memória, que atualiza o amplo debate sobre a aporia do testemunho, que atravessou, polemicamente, as últimas décadas, com uma força especial depois do famoso processo contra Adolf Eichmann em 196s. Foi pelo grau de problematicidade, mas também de seminalidade crítica, queoescolhemos tal conceito, como representativo dessm debate em curso.

Mas a que nos referimos quando falamos em pós-memória? E mais uma questão, que talvez seja mais específica, restrita ao contexto português de que tratamos: uma memória tão disputada e controversa como a da guerra colonial, qual pós-memória poderá engendrar? E um evento traumático como esse, longe de se fundamentar em políticas da memória compartilhadas, proporcionará um défice ou um excesso de pós memóri, (uma assimetria mnésica devida ao carácter problemático de um passado que não parece deixar-se reduzir em narrativas comunitárias ou públicas)? 
Será que a pós-memória tem os seus dias contados? Esta pergunta evoca o verso de "Finados", do poeta brasileiro Júlio Castañon Guimarães ("a memória tem os dias contados"), que, no auge da literatura memorialista dedicada aos anos de chumbo do autoritarismo, desafiava a possibilidade ingênua de pensar que as memórias das "vítimas" pudessem preencher os vácuos e os silêncios da história e fundar, de certo modo, uma memória compartilhada.

Problemática já a partir da sua morfologia, a pós-memória, como se sabe, surge em alguns trabalhos sobre a memória familiar, como o de Marianne Hirsch, que a partir do muito citado Family Frames, de 1997, começa a desenvolver uma reflexão crítica que configura a semântica da pós-memória. Os primeiros traços da proposta de Hirsch apontam para uma classificação um tanto genérica:

In my reading, postmemory is distingueshed from memory by generational distance and from history by deep personal connection. Postmemory is a powerful and very particular from of memory precisely because its connection to its object or source is mediated not through recollection but through an imaginative investment and creation [...]. I have developed this notion in relation to children of Holocaust survivors, but I believe it may usefully describe other second generation memories of cultural or collective traumatic events and experiences. (HIRSCH, 2002, p. 22)

Segunda geração de uma primeira de testemunhas - no sentido de testemunhas vivenciais, presenciais, oculares: parte, portanto, daquele conjunto complexo que hoje é a reflexão sobre o testemunho que foi marcada pela indizibilidade, pelos limites de representação de uma experiência traumática, tendo como referêncià extrema a Shoah.

No entanto, os planos inclinados de categorias críticas como memória e testemunho desestabilizam ainda mais a ideia de pós-memória. É por isso que muitos trabalhos sucessivos ao gesto fundador de Hirsch se concentram sobre uma refocalização do campo, na qual a pós-memória torna-se antes de tudo uma ocasião de reflexão sobre a memória, na tentativa - máscara ou fetiche-- de suprir as suas lacunas, preencher as suas incontáveis perdas. De facto, revisões mais recentes, sempre de Hirsch, tornam a categoria mais inteligível, não só poa sua reinscrição geracional, mas também porque, enquanto poderoso tipo de memória que surge mais do silêncio do que das palavras, se configura como "dimensão da recordação intersubjetiva" (HIRSCH, 2006, p. 392). Nesse aspecto, adotando a figura proposta por Geoffrey Hartman das “testemunhas adotivas", a pós-memória torna-se um "testemunho adotivo a posteriori" que instaura uma relação ética com a experiência do trauma ou da dor. A pós-memória, em suma, atesta uma distância que acaba por reafirmar, sempre nas palavras de Hirsch, "a natureza diferencial da própria recordação traumática" 
(HIRSCH, 2006, p. 393). Isto leva à afirmação, um tanto metafísica, de que, provavelmente,eapenas as gerações sucessivas conseguiriam recordar e elaborar o trauma. Além disso, tal hipótese confirmo um traço da experiência traumática, já proposto por Cathy Caruth, que diz respeitoaà dimensão intersubjetiva do trauma, que o converteria em um lugar de abertura -ou de encontro - com o outro. Se a ideia de uma memória a posteriori inscreve a pós-memoria numa constelação mais ampla, dominada pelos "pós” prefixais (pós-moderno, pós-colonial, etc.) -atornando ainda menos apreensível, mais ambíguo e teoricamente confus, o seu núcleo conceptual--, ela parece assim desempenhar, para quem a protagonizou, a função de restituição que, tragicamente, não se cumpre no processa de construção de uma memória da cena traumáticu, ou seja, o supérstite (que não consegue exercer a função de quem recorda).

Neste quadro escorregadio, há uma diluição de objetos que, embora instituam uma combinação criticamente densa - trauma, lembrança, memória -, na verdade são problematicamente redutíveia. Outros autores, como por exemplo James Young (At Memory's Edge), apropriam-se do conceito elaborado por Hirsch -adessa "memória da memória", uma memória em abisms - numa chave em que a dimensão singular da lembrança é adequadamente valorizada, distinguinds nela um duplo ato de lembrar, um ato próprio- a lembrança da experiência- e outr- vicárioo lembrança de vivências alheias, pela incorporação de narrações, imagens de alguém dentro da esfera privada - e é este segundo que nos interessa. Uma crítica inteligente e cortante ao conceito de pós-memoria é a elaborada pela estudiosa argentina Beatriz Sarlo, que nos proporciona outro campo analítico, na medida em que, em sua análise a referência histórica dos "desaparecidos" pela ditadura militar predomina sobre a da Shoao. Ao expor os eixos problemáticos da categorização da pós-memória, que a tornam "um gesto teórico mais amplo do que o necessário", Sarlo nota que "simplesmente se terá escolhido chamar pós-memória o discurso em que há o envolvimento da subjectividade de quem escuta o testemunho do seu pai, de sua mãe, ou sobre eles" (SARLO, 2007, p. 95).

Nessa perspectiva, a pós-memória induz uma reflexão sobre as formas de memória que não se prestam a uma elementar dicotomia entre titulares da experiência ou da vivência e os seus filhos, em virtude da qual o potencial de uma ideia de pós-memóri, não só não se reduz, mas pelo contrário, nesta reconfiguração crítica, amplifica-se, visto que, assim, "todo passado seria abordável somente por exercício de pós memória” (SARLO, 2007, p. 112-113). O que o debate sobre a pós-memória de certo modo e positivamente pressupõe é uma revisão dos protocolos da memóris e sobretudo uma redefinição do ses campo e das suas aporias. Se a cena foi dominada, pelo menos no pós-guerra e na pós-Shoah, pela busca obsessiva da definição de um paradigma do testemunho, a paisagem atual apresenta outros traços de problematização. No fundo, a abertura do carácter trágico do testemunho integral daquele que é o titular da experiência, mas não da representação, ${ }^{2}$ para outras configurações, como a performatividade ou 
a des-subjetivação e re-subjetivação proporcionadas pelo autor vicário do testemunho, explica as observações de Sarlo, que concentram na pós memória problemas da memória tout court.

O que é provavelmente relevante, na configuração da pós-memóriae é o fato de deslocar a testemunha, de uma esfera perturbada, como o espaço público queaela vem ocupando, para um outro paradigma - ou a transformação do primeiro-- inscrito no espaço privado, no círculo familiar, que seria o do pacto (e não contrato), como o define Annette Wierviorka, da compaixã). Na verdade, não se trata bem de um deslocamento: trata-se bem mais de uma extensão dos problemas da memória associados às aporias sempre mais evidentes do testemunho e dos modos pelos quais uma memória pública, a partir dos limites da recordação individual, pode começar a se constituir. Um traço que de facto fundaria a dimensão da pós-memória está presente e preenche a "era da testemunha" ou uma épo$\mathrm{ca}$ - a nossa-- em que as testemunhas vivenciaisocedem lugar a outro tipo de testemunho, indireto, mediador,acuja experiência já surge como representação.éEssa distinção implica dizer que o testemunho se configura mais como ato do que como facto (BIDUSSA, 2009, p. 25), justamente porque "fala para o coração, não para a razão" (WIEVIORKA, 1999, p. 153).eSe o lado performativo desse acto a ou não uma condição vantajosa ou prejudicial à construção de uma memória,étrata-se de um debate ainda em curso, no qual as duas posições são minuciosamente postas em confronto (e o caso Papon, evocado por Wieviorka, representaria o marco visível dessa transformação do testemunho como portador de memória, a sua transmissão para os historiadores e, sobretudo, para a geração seguinte, a das testemunhas depois das testemunhas, da memória traumática indireta, em suma, também problematicamente considerada pós-memória, como no caso de Esther Fogiel, referindo-se sempre ao processo Papon).

Assim, a dimensão da pós memória surgiria de facto dos desdobramentos da memória, dentro do conjunto de problematizações - e entraves-- que caracteriza o testemunho. Poder-se-ia observar, ainda, que o paradigma mitológico de Filomela (lembrando o "Philomela Project" de Geoffrey Hartman, ou seja, "the restoration of voice to inarticulate people", [HARTMAN, 1991, p: 169])asegue no centro da cena e das performances que procuram preencher a falha inexorável do testemunho. Tal traço torna-se evidente na literatura da "pós-memória" na qual afloram imagens, palavras, restos sensoriais do passado,(como por exemplo num romance dos mais emblemáticos, neste contexto, Austerlitz, de W. G. Sebal).

Mas como é que este problema de índole teórica repercute no caso do trauma e das síndromas pós-traumáticas originadas pela experiência da guerra colonial? Mais uma vez parece que estamos perante a questão-- clássica, diria-- ma singularidade de uma experiência históricaeaparentemente em condições de fundar uma excepção. Nessa situação, não temos, como no caso da Shoah, a matriz de um modelo de construção da memória. Ficaria em suspenso, pois, se o modelo basta para fundar também um saber. A tal pergunta daríamos provavelmente uma resposta negativa. 
A guerra colonial é, de facto, uma guerra ainda à procura de um nome - guerra colonial, guerra de África, guerra do Ultramar-e e a incapacidade de nomeá-la corresponde, num plano simbólico,aà incapacidade de pensá-la como fundadora de uma memória compartilhada. Mas não é só isto. É o evento final de uma errância colonial complexa e marcada por factos específicos, que não teve (ainda ou para sempre) inscrição - lembrando a definição de Portugal como "o País da não-inscrição", de José Gile E o que não se inscreveu foram as perdas,(não já a das colônias) mas sim as mutilações e cicatrizes- os traumas-efetivos e não só figurais que a essa guerra se associaram, o que de facto engendrou, como ocorre quando não se dá a inscrição e o luto não tem curso, um fantasma recorrente. Assim, um "branco psíquico" - a não inscrição-- passaria de geração em geração, como o "impensado genealógico" (lembrando Nicolas Abraham e Maria Torok) em termos metapsicológicos (GIl, 2005, p: 22).

Esta dificuldade percebe-se no debate atual sobre a não-inscrição da guerra colonial - portanto a sua "visibilidade" enquanto rasto histórico-como elemento próprio do pós-colonialismo português. Há também uma outra característica que complica a prática da memória no que se refere ao conflito de "Portugal contra a sua história" (como se diria retoricamente). Isto decorre da denegação da guerra colonial enquanto evento ou facto que pode polarizar a memória, mas tem cidadania ou representação no espaço público. A dinâmica própria da guerra, submetida a uma estratégia de apagamento ou desbotamento dos seus rastos na história, impediu que se pudesse tornar pre,ente o "futuro do passado". Em multíplices sentidos, a guerrauconsumou-se numa esfera oikonomica e não política, numa dimensão internalizada (nas vísceras da nação "pluricontinental" que incluía os apêndices ultramarinos), mas que também se refletiu na posição de Portugal em relação à comunidade das outras nações, inclusive aquelas com que tinha compartilhado o projeto imperialista. Diria mais, o impacto traumático se projetou em particular dentro de uma dimensão sobretudo familiar e não propriamente comunitária. Assim, as experiências traumáticas ficaram como encapsuladas nas "criptas" familiares, como bem se depreende de filmes pioneiros sobre a guerra colonial, qual por exemplo Um adeus português, de João Botelho. A pós-memória, num contexto de memória perturbado como este, não passaria de mais uma oclusão para que a recordação se transformassr em memória, tendo já na própria consistência fragmentária da pós-memoria, pela sua condição "em abismo", uma resistência para ir além da narrativa egótica e tornar-se espaço mnésico comunitário.

No entanto, a reflexão sobre a pós-memória da guerra colonial, embora muito problemática e num certo sentido trágica pelos extremos que expõe, levanta uma possibilidade de configuração da memória que o projeto do CES-UC tenta valorizar,opor via dos estudos culturais e da estreita conexão instaurada com a pesquisa psiquiátricar Chamaria esta possibilidade uma inscrição (póstuma) da não inscrição de vivência e de even- 
tos traumáticos, inscrição esta que se realiza no círculo familiar. De facto, perante a questão relevante da existência ou não da memória coletiva (pense-se nas restrições de Susan Sontag e de Reinhart Kosellek sobre a irredutibilidade da recordação individual), o que revela Aleida Assmann, pelo contrário, é que a inscrição física, corpórea da memória, feita por feridas e cicatrizes, é muito mais fiel do que a memória mental (ASSMANN, 2002, p. 275). O que permite, depois, a fundação de uma memória compartilhável a partir da impressão individual da dor é uma passagem relevante "do físico ao metafísico", que corresponde a uma metaforização capaz de conferir um valor paradigmático à experiência individual (MAJ, 2004, p. 29). São de facto, como bem mostra o filosofo Paolo Virno, refletindo a partir de Adorno sobre a instância profunda dos materialistas, as impressões do prazer e da dor que, trivial mas materialmente, recolocam, de modo constante e de certa forma polémicoa a imagem do corpo que sente sofrimento ou prazer, em relação à lógica ou à metafísica, privilegiando,oem alguma medida, a aisthesis sobre o logos, a sensação sobre o discurso (VIRNO, 1992, p. 59). Aqui, as narrações resgatadas da esfera privada (as entrevistas) funcionariam de certo modo como o medium decisive, de acordo com Hirsch mas também com Sebald, para a construção da pós-memória, que é o território das imagens, das fotografias ("imagetexts"). E a guerra colonial, apesar das suas singularidades, funda-se sobretudo sobre um grande arquivo de fotografias.éÉ sempre duplo o regime que caracteriza certas imagens, certas palavras, um excesso ou um defeito, uma distância ou uma proximidade, um sentido imediato e outro cifrado, complexo, inapreensível. É com essa oscilação nem precisamente dialéctica - bem mais um "palpite" - que tal regime remete para a definição das assim chamadas "imagens-arranco" (que se opõem à ideia platônica da imagem-véu, mas que são próximas no entanto das imagens dialécticas). Como acontece com os signos, as imagens produzem um efeito através da sua negação (DIDI-HUBERMAN, 2005, p. 106): são as imagens "apesar de tudo" de George Didi-Huberman. A imagem surgiria, assim, do silêncio e da falência de pensamento, "onde todas as palavras se calam e todas as categorias fracassam, imagens-arranco no sentido que o real encontra no arranco a possibilidade de passagem, de representação pela obstrução" (DIDI-HUBERMAN, 2005, p. 107). Para um contexto como o da guerra colonial, ainda longe de se contratualizar socialmente no plano da memória colectiva, no qual ainda domina a convicção de que a legitimidade da sua representação pertence só aos titulares da experiência direta (sem considerar que assim os traumas nunca poderão, pelo ato vicário da memória e da representação testemunhal, chegar a qualquer representação), a constelação testemunho-pós-memória-transferência da memória pode funcionar como uma ferramenta crucial para repensar o que foi a guerra colonial para grupos socialmente relevantes da sociedade portuguesa e, além disso, que efeitos, visíveis ou invisíveis, provocou dentro da sociedade, nas gerações seguintes, embora ainda não exista uma narrativa consensual sobre o que a guerra efetivamente foi. 
À guerra colonial em África falta ainda a compaixão como pacto intergeracional dentro da esfera familiar, e que funciona como pressuposto para a sua contratualização no espaço público. De facto, como analisa Martha Nussbaum em A inteligência das emoções, a compaixão, ainda que não represente a totalidade da racionalidade pública (no liberalismo político baseado no "consenso por intersecção", [NUSSBAUM, 2004, p. 479]) tem um papel significativo em plasmar a compreensão colectiva perante os traumas socialmente relevantes (NUSSBAUM, 2004, p. 539) que reconfiguram o espaço público. Esta investigação combina duas dimensões analíticas. A primeira diz respeito a recolha de testemunhos da segunda geração, que se expõem através de obstruções, reflexos, ecos, cacos das memórias traumatizadas. A segunda, não menos importante, se dedica à apreciação da produção artística e cultural da pós-memória, fenômeno não só em curso mas em clara fase de expansão. Poemas (penso sobretudo na obra de Norberto do Vale Cardoso), Cinema (como Margarida Cardoso da Costa dos Murmúrios) e, sobretudo, no campo musical (um campo de certo modo privilegiado, como ensina o hip hop, para tornar visível o indizível da dor por uma aliança entre palavra, música e técnica a baixo custo). A produção artística dos filhos da guerra é importante não só porque contribui para fundar o campo da compaixão (que possibilita algum testemunho) em torno dos traumas da guerra, mas também porque, pelas mitologias familiares que elabora e projeta, tornando-se comunicação - , reinscreve no espaço público a dimensão da pós-memória, que, como vimos,oestá circunscrita por seu carácter individual e, frequentemente, intransitivo. Lembrando o mito clássico,Oo trabalho de Filomelo, que borda o que a sua impossibilidade de fala lhe impede dizer - os fatos violentos experienciados - encontra assim um seu correlativo viável. Portanto, apesar de tudo, pós-memória.

Finalmente, se esta configuração da pós memória, e do suplemento de ato de autor que dela se origina, efetivamente funciona, a memória pública de uma experiência traumática como a da guerra colonial tonar-se-ia possível. Não só, mas o impasse da transmissão/transferência da memória assim simbolizada para as novas gerações seria de certo modo superado, através de uma pedagogia da reelaboração da história como trauma - não reduzida a lembranças apenas- mas projetada politicamente no espaço público. Isto contratualiza a compaixão própria do testemunho e da pós-memória e, em simultâneo, dissemina representações de uma memória nova que ressignifica, não melancolicamente, as perdas e os vácuos do passado, ou, como cantam os Xutos \& Pontapés, redeclinando e reinscrevendo as memórias incômodas do que se passou, lá em África, nem muito tempo atrá:: "Aguenta essa saudade por alguém/ Que ficou para trás” (Inferno (O film)], Parte 2. Xutos \& Pontapés, 2001). 


\section{REFERÊNCIAS BIBLIOGRÁFICAS}

ASSMANN, Aleida. Ricordare. Forme e mutamenti della memoria culturale. Bologna: il Mulino, 2002.

BIDUSSA; David. Dopo l'ultimo testimone. Torino: Einaudi, 2009.

DIDI-HUBERMAN, Georges. Immagini malgrado tutto. Milano: Raffaello Cortina, 2005.

GIL, José. Portugal, hoje: o medo de existir. 3. ed. Lisboa: Relógio d’Água, 2005.

HARTMAN, Geoffrey H.. Minor Prophecies. The Literary Essay in the Culture Wars. Cambridge-London: Harvard University Press, 1991.

HIRSCH, Marianne. Family Frames: photography, narrative, and postmemory. 2. ed. Cambridge and London: Harvard University Press, 2002.

Immagini che sopravvivono: le fotografie dell'Olocausto e la post-memoria. In: CATTARUZZA, Marina et al. (orgs.) Storia della Shoah. La crisi dell'Europa, lo sterminio degli ebrei e la memoria del XX secolo. Torino: UTET. V. III, 2006, p. 384-421.

MAJ, Barnaba (2004) Lendas, lembranças e memória. In: VECCHI, Roberto; ROJO, Sara (orgs.). Transliterando o real: diálogos sobre as representações culturais entre pesquisadores de Belo Horizonte e Bologna. Belo Horizonte: UFMG/FALE, 2004, p. 29-31.

NUSSBAUM, Martha. L'intelligenza delle emozioni. Bologna: il Mulino, 2004.

SARLO, Beatriz Tempo passado: cultura da memória e guinada subjetiva. São Paulo: Companhia das Letras; Belo Horizonte: Editora da UFMG, 2007.

VIRNO Paolo. I rompicapo del materialista. In: AA.VV. Il filosofo in borghese, Roma: Manifestolibri, 1992, p. 57-66.

WIEVIORKA, Annette. L'era del testimone. Milano: Raffaello Cortina, 1999.

Recebido para publicação em 15/04/2013

Aprovado em 22/07/2013

\section{NOTAS}

1 Do projeto interdisciplinar, financiado em Portugal pela Fundação de Ciência e Tecnologia (FCT) e o Ministério da Defesa, participaram os pesquisadores seniores António Sousa Ribeiro, Luísa Sales, Rui Mota Cardoso e o autor do presente texto.

2 De acordo com uma famosa reflexão que encontra o seu limiar lúcido em Primo Levi. 